\title{
DETERMINATION OF STRONTIUM IONS IN WATERS WITH A HIGH CONTENT OF SODIUM IONS
}

\author{
Tatiana Mitina*, Nadejda Bondarenco, Diana Grigoras, Elena Botizat, Tudor Lupascu \\ Institute of Chemistry of Academy of Sciences of Moldova, 3 Academiei str., Chisinau MD-2028, Republic of Moldova \\ *e-mail: mitina_tatiana@mail.ru; phone / fax (+373 22) 739977
}

\begin{abstract}
This paper reports on the influence of sodium ions on experimental determination of strontium ions concentration in waters with a high content of sodium ions by using emission flame photometry and atomic absorption spectroscopy. For the method of emission flame photometry it was shown that at a wavelength of $460.7 \mathrm{~nm}$ (spectral emission line of strontium) the emission is linearly dependent on the concentration of sodium ions. The greatest impact of high concentrations of sodium ions on the result of determination the strontium ions concentration has been registered at low levels of strontium. The influence of nitric acid on the results is also discussed. In the case of using atomic absorption spectroscopy method no influence of sodium ions and nitric acid on the results of determination the strontium ions concentration was revealed. The metrological characteristics of both methods are evaluated.
\end{abstract}

Keywords: water analysis, strontium ions, emission flame photometric method, atomic absorption spectroscopy.

Received: June 2014/ Revised final: October 2014/ Accepted: November 2014

\section{Introduction}

Strontium is a micro-component of waters. The negative effects of elevated strontium on human health are well established. Being close to the chemical properties of calcium, strontium sharply differs in its biological action. Excess levels of this element in water cause the substitution of calcium in the bones, liver and brain. This pathology is a reflection of the competitive relations of strontium and calcium in their distribution in the body [1]. Despite the fact that strontium content in drinking water is not regulated by the Governmental Decision No. 934 from 15.08.2007, according to GOST 2874-82 strontium content must not exceed $7 \mathrm{mg} / \mathrm{L}$. The US EPA (United States Environmental Protection Agency) has set three health advisory levels for strontium: a Lifetime Health Advisory Level (Lifetime HAL), a oneday Health Advisory Level (One-Day HAL), and at ten-day Health Advisory Level (10-Day HAL). HALs serve as an estimate of acceptable levels in drinking water [2]. They are used by Federal, State, and local officials, when making decisions about the safety of the drinking water supply. The HALs for strontium are defined as:

- Lifetime $\mathrm{HAL}=4 \mathrm{mg} / \mathrm{L}$ : a person drinks this level (or lower) their entire life and is not expected to develop any health problems related to strontium exposure.

- One-Day HAL $=25 \mathrm{mg} / \mathrm{L}$ : the level for which a child, drinking $1 \mathrm{~L}$ of water in a day, would not be expected to develop any related to strontium exposure health problems.

- Ten-Day HAL $=25 \mathrm{mg} / \mathrm{L}$ : the level for which a child, drinking $1 \mathrm{~L}$ of water per day for ten days, would not be expected to develop any related to strontium exposure health problems.

The evaluation of strontium content in drinking water, especially in Moldova, is necessary because its content in groundwater in some areas exceeds the permissible concentration [3]. In order to determine the strontium in water, the following standardized methods are used: emission flame photometric method [4], the method using capillary electrophoresis [5] and the method of atomic emission spectroscopy with inductively coupled plasma [6, 7]. One of the most affordable and widely used methods is emission flame photometric strontium determination. However, this method is applied to drinking water and does not take into account the influence of sodium ions on the determination of strontium from its spectral emission line $(\lambda=460.7 \mathrm{~nm})$.

Evidence of water micro-components on the background of high concentrations of its major components is always associated with the possibility to get doubtful results, due to the occurrence of spectral and matrix effects. We have studied the effect of sodium ions on the result of determination the strontium ions concentration, by using emission flame photometry. As known, sodium is a macro-component of water and its content in drinking water in Moldova is limited to a concentration of $200 \mathrm{mg} / \mathrm{L}$. The results of our research show that concentration of sodium in the waters of Moldova is highly variable and can range from small values to concentrations far exceeding the maximum permissible value. In the present study we have evaluated the use of flame emission photometry method for determining the concentration of strontium ions in water in the presence of various concentrations of sodium ions.

\section{Experimental}

All experimental work on the determination of strontium ions concentration by flame photometry were performed on an atomic absorption spectrometer AAS-1 (mode-emission) in a flame of propane-butane-air at a wavelength of $\lambda=460.7 \mathrm{~nm}[4]$.

Model solutions containing strontium ions with concentrations of 1.0, 2.5, 5.0, 7.5, $10 \mathrm{mg} / \mathrm{L}$ were prepared from a standard sample ISS 0148:200, certified mass concentration of strontium ions $1 \mathrm{mg} / \mathrm{cm}^{3}$ and a relative error of less than 
$1 \%$ with a probability of $0.95 \%$ (Ukraine). The background is a solution containing sodium ions with concentrations of $0,23,46,92,230,575$ and $1150 \mathrm{mg} / \mathrm{L}$, prepared from a standard of $0.1 \mathrm{M} \mathrm{NaCl}$. In these solutions we have added nitric acid 1:5 (1 mL to $100 \mathrm{~mL}$ of sample) and lanthanum buffer $\left(2.5 \mathrm{~mL} \mathrm{La}^{3+} 100 \mathrm{mg} / \mathrm{L}\right.$ to $100 \mathrm{~mL}$ of sample).

The graphs of the emission intensity as function of strontium ions concentration coincide at given sodium ions concentrations of $0,23,46$ and $92 \mathrm{mg} / \mathrm{L}$.

\section{Results and discussion}

The influence of sodium ions begins at a concentration of $230 \mathrm{mg} / \mathrm{L}$. Figure 1 shows the effect of sodium ions on the intensity of strontium emission.

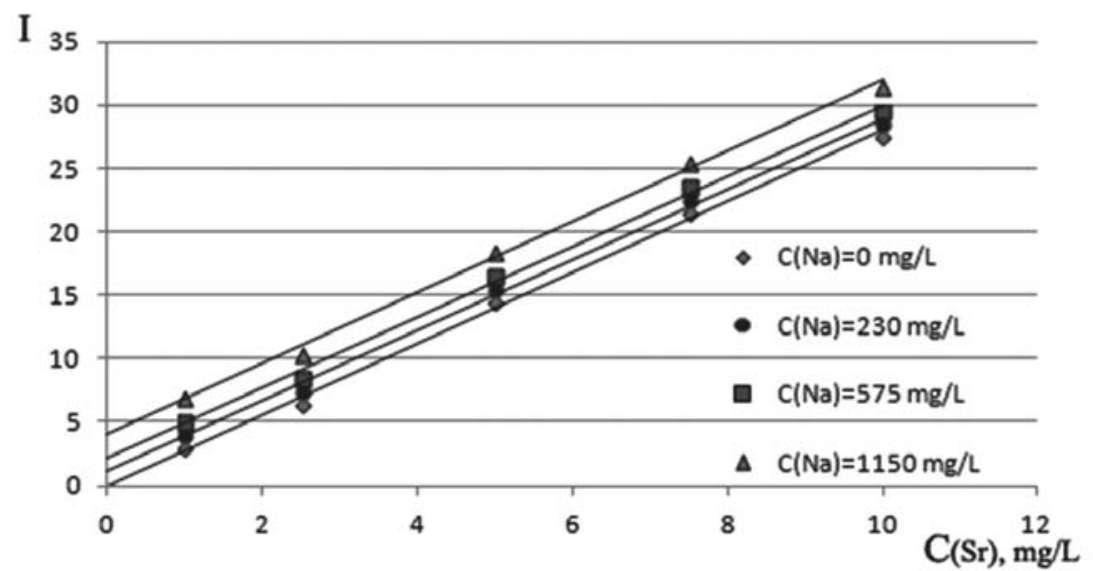

Figure 1. Dependence of emission intensity of strontium ions upon their concentration at various sodium contents.

The dependence of emission intensity of strontium ions concentration is linear for different sodium contents and is described by the equation $\mathrm{y}=\mathrm{a} \cdot \mathrm{x}$, when the background solution contains sodium ions at a concentration of less than $230 \mathrm{mg} / \mathrm{L}$ and by the equation $\mathrm{y}=\mathrm{a} \cdot \mathrm{x}+\mathrm{b}$ in the case, when sodium ions are presented at concentrations above $230 \mathrm{mg} / \mathrm{L}$. The correlation coefficient ranged from 0.997 to 1 .

Figure 1 shows that increase of sodium ion concentration enhances the strontium ions emission intensity.

Figure 2 shows the dependence of the emission intensity on the concentration of sodium ions at a wavelength $\lambda=460.7 \mathrm{~nm}$. The graph is linear over the sodium concentration range $0-1150 \mathrm{mg} / \mathrm{L}$.

According to Figures 1 and 2, the presence of sodium ions in model solutions increases the emission intensity that was measured at strontium spectral emission line $(\lambda=460.7 \mathrm{~nm})$.

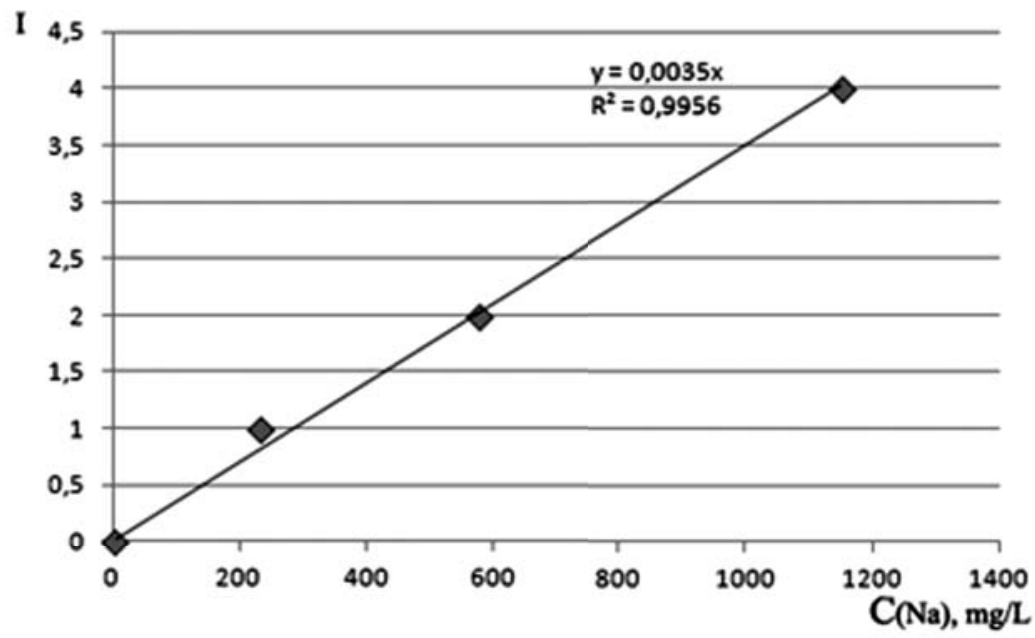

Figure 2. Emission intensity of sodium ions at $\lambda=460.7 \mathrm{~nm}$.

Figure 3 shows dependence of the total emission intensity to the intensity of radiation of strontium ions at various sodium ions concentrations. 
Figure 3 demonstrates that sodium ions at concentrations above $200 \mathrm{mg} / \mathrm{L}$ have a marked effect on the result of determination the strontium ions concentration. It should be noted, that this effect greatly increases at low strontium concentrations. Thus, the detected signal for strontium (concentration $1.0 \mathrm{mg} / \mathrm{L}$ ) increases by 1.33 times in the presence of sodium ions concentration of $230 \mathrm{mg} / \mathrm{L}$, increases by 1.66 times when the concentration of sodium ions is $575 \mathrm{mg} / \mathrm{L}$ and by 2.33 times at a concentration of sodium ions of $1150 \mathrm{mg} / \mathrm{L}$.

Thus, the effect of sodium, which is caused by nonspecific radiation, augments with decreasing the strontium concentrations.

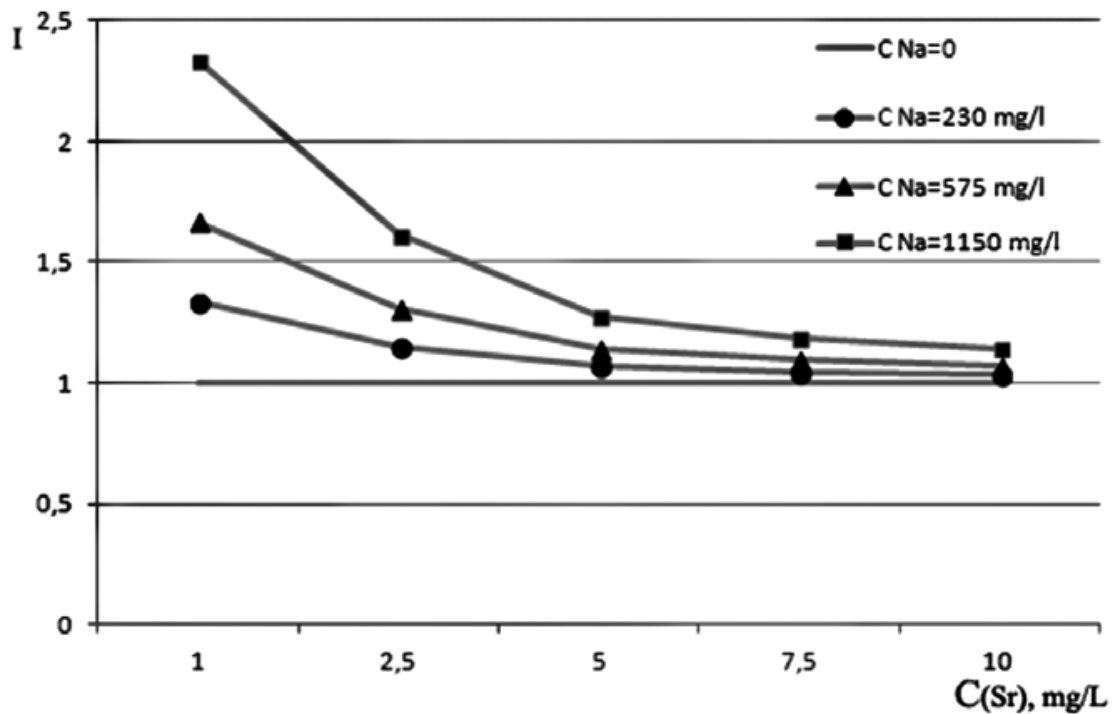

Figure 3. Dependence of the total emission intensity to the emission intensity of strontium ions at various concentrations of sodium ions.

Besides model solutions, in order to study the effect of sodium ions in the determination of strontium ions concentration by flame photometry, the natural mineral water Soroca was used, with a sodium content of $1.5 \mathrm{~g} / \mathrm{L}$. Strontium in this sample was determined: 1) without considering the background, 2) taking into account the background and 3) using the method of supplementation. Using the calibration graph plotted from reference solutions containing no sodium ions, strontium concentration was found $1.8 \mathrm{mg} / \mathrm{L}$. At the same time, if we consider the background emission (sodium ion concentration of $1.5 \mathrm{~g} / \mathrm{L}$ ), the content of strontium in the test water is less than $0.5 \mathrm{mg} / \mathrm{L}$.

In order to assess the correctness of strontium ions determination, the method of additions was used. The graphs for the addition method were plotted with and without taking into account the background radiation (Figures 4 and 5).

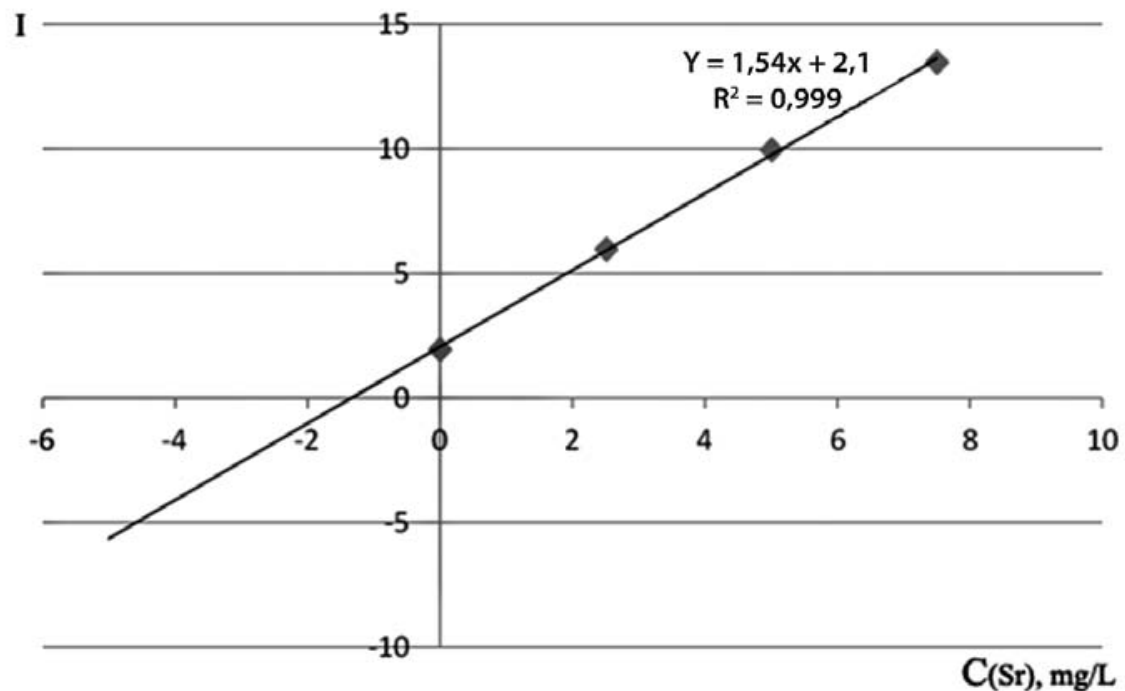

Figure 4. Method of additions without considering the background (water Soroca). 
I

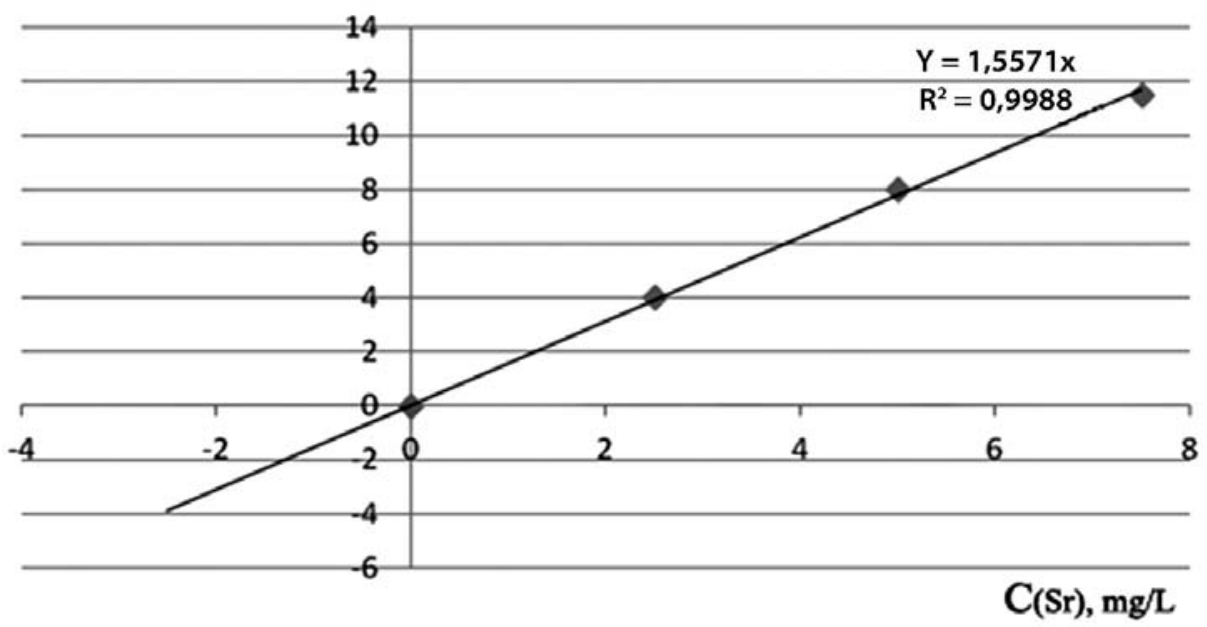

Figure 5. Method of additions taking into account the background (water Soroca).

Strontium ions content that was determined by excluding the background is $1.3 \mathrm{mg} / \mathrm{L}$, as opposed to $0.5 \mathrm{mg} / \mathrm{L}$, when the background is considered.

Thus, in the case of interfering effect that was caused by a non-selective emission of sodium ions, the method of addition may be applied, if the background emission is taken into account. The results of determination the strontium ions concentration, which were obtained by direct determination, are in good agreement with the results obtained by the addition method, taking into account the background.

In addition, we have shown the effect of nitric acid on the results of determination the strontium ions concentration by flame photometry. According to GOST 23950-88, nitric acid is added in standard solutions and samples $(1: 5,10 \mathrm{~mL}$ per one liter of sample), i.e. its concentration is $0.03 \mathrm{~N}$.

Increasing the nitric acid concentration by $0.04 \mathrm{~N}$ (to $0.07 \mathrm{~N}$ ) leads to the suppression of strontium signal by $20 \%$, while increasing the nitric acid concentration by $0.05 \mathrm{~N}$ (up to $0.075 \mathrm{~N}$ ) leads to the suppression of the signal by $21 \%$. Hence, using the method of flame photometry it is important to align the content of nitric acid in the samples and standards. This is particularly important in the determination of strontium ions concentration in the conserved waters, where $5 \mathrm{~mL}$ of concentrated nitric acid per $1 \mathrm{~L}$ of sample are usually added, to achieve a $\mathrm{pH}<2$. Nitric acid concentration in these samples is $0.075 \mathrm{~N}$.

Besides the method of flame photometry, we have employed the method of atomic absorption determination of strontium ions in water, which is not standardized [8].

Assays were performed with an atomic absorption spectrometer AAS-1N in the flame of acetylene-air at a wavelength of $\lambda=460.7 \mathrm{~nm}$ and $5 \mathrm{~mA}$ current of the hollow cathode lamp.

In the analysis of model solutions with different concentrations of sodium and natural mineral water Soroca, no effect of sodium on strontium absorption was found. Analogically, we observed no effect of nitric acid on the result of strontium ions determination.

The concentration of strontium ions in the mineral water Soroca, which was determined by atomic absorption spectrometry, was less than $0.5 \mathrm{mg} / \mathrm{L}$, as in the case of flame photometric method, when the background was taken into account.

Metrological parameters of both methods were determined on model solutions with the content of sodium ions of $1150 \mathrm{mg} / \mathrm{L}$ and the content of strontium ions of $2 \mathrm{mg} / \mathrm{L}$ and $5.0 \mathrm{mg} / \mathrm{L}$ [9]. The accuracy of obtained by both methods results is presented in the Table 1 .

Table 1

The accuracy in determining the strontium ions concentration by flame photometry, considering the background emission, and by atomic absorption spectrometry.

\begin{tabular}{c|cc|c|c}
\hline \multirow{2}{*}{$\begin{array}{c}\text { Strontium } \\
\text { concentration, }\end{array}$} & \multicolumn{2}{|c|}{$\begin{array}{c}\text { Flame photometry, considering the } \\
\text { background emission }\end{array}$} & \multicolumn{2}{c}{ Absorption spectrometry } \\
\cline { 2 - 5 }$m g / L$ & Found, $\mathrm{mg} / \mathrm{L}$ & Divergence, $\%$ & Found, $\mathrm{mg} / \mathrm{L}$ & Divergence, \% \\
\hline 2.0 & 1.97 & 1.50 & 2.03 & 1.49 \\
5.0 & 5.11 & 2.17 & 5.07 & 1.39 \\
\hline
\end{tabular}

The variation coefficient of flame photometry for the determination of strontium in water is $6.3 \%$, of atomic absorption $-4.5 \%$, the detection limit for both methods is $0.5 \mathrm{mg} / \mathrm{L}$. Thus, for the determination of strontium by flame 
photometry it's necessary to consider the background emission and align the concentration of nitric acid in the sample solutions and standards. To determine strontium in waters of unknown composition and water samples preserved with nitric acid, it's preferably to use atomic absorption spectrometry.

\section{Conclusions}

The influence of sodium ions and nitric acid on experimental determination of strontium ions concentration in waters by using emission flame photometry and atomic absorption spectroscopy has been investigated, being also evaluated metrological characteristic of both methods.

The evaluation of the use of flame emission photometry method for determining the concentration of strontium ions in water, the following remarks can be outlined: high sodium content in water leads to an overestimation of the results of determination strontium; at wavelength of $460.7 \mathrm{~nm}$ (spectral emission line of strontium) the emission is linearly dependent on the concentration of sodium ions; obtained results showed suppressing influence of nitric acid on the determination of strontium ions.

In the case of using atomic absorption spectroscopy method no influence of sodium ions and nitric acid on the results of determination the strontium ions concentration was revealed.

In conclusion, for the determination of strontium by flame photometry it is necessary to consider the background emission and align the concentration of nitric acid in the sample solutions and standards. To determine strontium in waters of unknown composition and preserved with nitric acid water samples, it is preferably to use atomic absorption spectrometry.

\section{References}

1. Sudia, D.A.; Lastkov, D.O. Problem toxicological actions of stable strontium salts on the organism. Modern problems of toxicology of food and chemical safety, 2013, 62(3), pp. 55-60 (in Russian).

2. The Potential Regulatory Implications of Strontium. American Water Works Association, http://www.awwa.org/ Portals/0/files/legreg/documents/2014AWWAStrontiumBriefingPaper.pdf

3. Mitina, T.; Bondarenco, N.; Bunciuc, O. The study of chemical composition and evaluation of groundwater quality in some regions of Moldova. Chemistry Journal of Moldova, 2012, 7(2), pp. 89-92.

4. GOST 23950-88. Drinking water. Emission flame photometric method for the determination of strontium. (in Russian).

5. GOST R 31869:2012. Water. Methods for the determination of cations (ammonium, barium, potassium, calcium, lithium, magnesium, sodium, strontium) using capillary electrophoresis (in Russian).

6. ISO/WD 11885:2003 Water Quality. Determination of 33 elements by inductively coupled plasma atomic emission spectroscopy (ICP-OES) (Revision of ISO 11885:1996)

7. GOST R 51309-99 Determination of elements by atomic spectroscopy (method of atomic emission spectroscopy with inductively coupled plasma). (in Russian).

8. Poluektov, N.S; Mishcenko, V.T. Analytical chemistry of strontium. Nauka: Moskow, 1978, 223 p. (in Russian).

9. ISO 5725-(1-6)-2002 Accuracy (trueness and precision) of determination methods and results. 